\title{
Effects of flow rate and chemical oxygen demand removal characteristics on power generation performance of microbial fuel cells
}

\author{
D. F. Juang $\cdot$ P. C. Yang $\cdot$ T. H. Kuo
}

Received: 3 August 2011/Revised: 20 September 2011/ Accepted: 21 November 2011/Published online: 7 March 2012

(C) CEERS, IAU 2012

\begin{abstract}
Two microbial fuel cells with different oxygen supplies in the cathodic chamber were constructed. Electrogenic capabilities of both cells were compared under the same operational conditions. Results showed that binary quadratic equations can express the relationships between chemical oxygen demand degradation rate and chemical oxygen demand loading and between chemical oxygen demand removal rate and chemical oxygen demand loading in both cells. Good linear relationships between power output (voltage or power density) and flow rate and between power output and chemical oxygen demand degradation rate were only found on the cell with mechanical aeration in the cathodic chamber, but not on the cell with algal photosynthesis in the cathodic chamber. The relationships between power output and chemical oxygen demand removal rate and between power output and effluent chemical oxygen demand concentration on both cells can be expressed as binary quadratic equations. The optimum flow rates to obtain higher power density and higher Coulombic efficiency in the cell with mechanical aeration in the cathodic chamber $\left(=0.85 \mathrm{~mW} / \mathrm{m}^{2}\right.$ and
\end{abstract}

\section{F. Juang}

Department of Health Business Administration,

Meiho University, 23, Pingguang Rd., Neipu,

Pingtung 912, Taiwan, Republic of China

\section{P. C. Yang}

Otorhinolaryngologic Department,

Cheng Ching General Hospital,

118, sec. 3, Chung Kang Road, Taichung 407,

Taiwan, Republic of China

T. H. Kuo $(\bowtie)$

New Taipei City Hospital Banciao Branch, 198, Yingshi Rd., Banqiao Dist., New Taipei City 220, Taiwan, Republic of China e-mail: nephguo@yahoo.com.tw
$0.063 \%)$ and in the cell with algal photosynthesis in the cathodic chamber $\left(=0.65 \mathrm{~mW} / \mathrm{m}^{2}\right.$ and $\left.0.05 \%\right)$ are about 1000 and $1460 \mu \mathrm{L} / \mathrm{min}$, respectively. The optimum chemical oxygen demand removal rates to obtain higher power density and higher Coulombic efficiency in the cell with mechanical aeration in the cathodic chamber $\left(=1.2 \mathrm{~mW} / \mathrm{m}^{2}\right.$ and $0.064 \%$ ) and in the cell with algal photosynthesis in the cathodic chamber $\left(=0.81 \mathrm{~mW} / \mathrm{m}^{2}\right.$ and $\left.0.051 \%\right)$ are about 40.5 and $36.5 \%$, respectively.

Keywords Anodic chamber - Cathodic chamber . Coulombic efficiency $\cdot$ Power density $\cdot$ Proton

\section{Introduction}

A microbial fuel cell (MFC) uses microorganisms to catalyze the conversion of organic matters into electricity (Kim et al. 2002; Oh et al. 2004; Logan and Regan 2006; Dewan et al. 2010). An MFC normally contains an anodic chamber and a cathodic chamber separated by a proton exchange membrane (PEM) or an ion-selected membrane (You et al. 2006). Bacteria will use the organic matter in an anodic chamber to produce electrons and protons. The electrons will then be diverted toward an anode and subsequently flow across a conductive material containing a resistor, and finally be released in a cathodic chamber. The protons will also migrate to the cathode through PEM. Both electrons and protons will finally be depleted in the cathode chamber, coupled with the reduction of oxygen to water (Kim et al. 2002; Logan 2005; Rabaey and Verstraete 2005; Oh and Logan 2006; Ieropoulos et al. 2010).

The power output of an MFC strongly depends on the oxygen concentration level in its cathodic chamber. Gil et al. (2003) studied the effect of dissolved oxygen (DO) 
concentration in the cathodic chamber on the power production performance of MFC. They concluded that DO concentration is around $6 \mathrm{mg} / \mathrm{L}$ at DO-limited conditions. Kang et al. (2003) suggested that the critical oxygen concentration is $6.6 \mathrm{mg} / \mathrm{L}$ for the graphite cathode. This means that the current generation of MFC is oxygen-limited when DO concentration in the cathodic chamber is below $6.6 \mathrm{mg} / \mathrm{L}$. Pham et al. (2004) also concluded that further increase in power density is not observed when DO concentration is over $6.6 \mathrm{mg} / \mathrm{L}$. Cha et al. (2009) reported that at the very low DO concentration of $0.2 \mathrm{mg} / \mathrm{L}$, the voltage of MFC remained at a high level of $200 \mathrm{mV}$ when the oxygen remained close to the cathode and mixing was sufficient.

In the study conducted by Rodrigo et al. (2010), maximum power density increased as DO concentration in the cathodic chamber increased from 0 to $5.5 \mathrm{mg} / \mathrm{L}$. In the foregoing studies, oxygen in the cathodic chamber was always supplied by mechanical aeration for a dual-cell MFC or by atmospheric air for a single-cell MFC, with the cathode directly exposed to air.

A photosynthetic MFC is defined when sunlight is converted into electricity within the metabolic reaction scheme of an MFC. In the review article of Rosenbaum et al. (2010), they reported that seven different configurations of photosynthetic MFCs have been applied by researchers to generate electricity or to decrease $\mathrm{CO}_{2}$ concentration in the atmosphere. Strik et al. (2008) applied a photosynthetic algal MFC to produce a maximum current density of $539 \mathrm{~mA} / \mathrm{m}^{2}$ (projected anode surface) and a maximum power production of $110 \mathrm{~mW} / \mathrm{m}^{2}$ (surface area of MFC). Schamphelaire and Verstraete (2009) used a closed-loop system consisting of an algal growth unit for biomass production, an anaerobic digestion unit to convert biomass to biogas, and an MFC to polish the effluent of the digester and to generate electricity. They claimed that this system resulted in a power plant with a potential capacity of about $9 \mathrm{~kW} / \mathrm{ha}$ of solar algal panel, with prospects of $23 \mathrm{~kW} / \mathrm{h}$. Wang et al. (2010) used two identical doublechamber microbial carbon capture cells (MCCs) to study their power performance and $\mathrm{CO}_{2}$ elimination capability. The MCCs were similar to the MFCs with algae growing in cathodic chambers. Oxygen in the cathodic chamber is obtained by the photosynthesis of algae in the sunlight. The results of their study showed that a voltage of $706 \pm 21 \mathrm{mV}(1000 \Omega)$ was obtained in the systems with a cathodic DO of $6.6 \pm 1.0 \mathrm{mg} / \mathrm{L}$.

You et al. (2006) showed that longer hydraulic retention time (lower flow rate) of MFC is more effective at COD removal but have a detrimental effect on voltage stability when compared with short hydraulic retention time. However, Ieropoulos et al. (2010) reported that the highest power output is produced at the lowest flow rate in MFCs.
In this study, power generation capabilities of microbial fuel cells with different oxygen supplies (mechanical aeration and photosynthesis of algae) in the cathodic chamber were evaluated. Effects of flow rate and COD removal characteristics on the power output and Coulombic efficiency of the MFCs with different oxygen supplies were also investigated. This study was conducted at the laboratory of Meiho University in Taiwan from February 2011 to May 2011.

\section{Materials and methods}

Synthetic wastewater and sludge source of MFCs

During the experimental period, the compositions and the concentrations of synthetic wastewater for both MFCs (MFCs 1 and 2) were $1000 \mathrm{mg} / \mathrm{L}$ glucose, $300 \mathrm{mg} / \mathrm{L}$ nutrient broth, $167 \mathrm{mg} / \mathrm{L} \mathrm{NH} \mathrm{NH}_{4} \mathrm{Cl}, 25 \mathrm{mg} / \mathrm{L} \quad \mathrm{K}_{2} \mathrm{HPO}_{4}, 25 \mathrm{mg} / \mathrm{L} \mathrm{NaH}{ }_{2} \mathrm{PO}_{4}$, $5 \mathrm{mg} / \mathrm{LFeCl}_{3}, 100 \mathrm{mg} / \mathrm{L} \mathrm{MgCl}_{2}, 10 \mathrm{mg} / \mathrm{L} \mathrm{MnSO}_{4}, 133 \mathrm{mg} / \mathrm{L}$ $\mathrm{CaCl}_{2}, 25 \mathrm{mg} / \mathrm{L} \mathrm{NaOH}$, and $175 \mathrm{mg} / \mathrm{L} \mathrm{NaHCO}_{3}$ (Juang and Chiou 2007). The COD of synthetic wastewater was between 1002 and $1296 \mathrm{mg} / \mathrm{L}$.

Original sludge was obtained from the oxidation ditch of a wastewater treatment plant located in Ping Tung, Taiwan. It was grown in $1 \mathrm{~L}$ of synthetic wastewater without aeration, and was allowed to acclimatize for 2 weeks. The sludge liquid was then transferred to the anode chambers of both MFCs in equal quantity. By feeding with synthetic wastewater at the rate of $350 \mu \mathrm{L} / \mathrm{min}$, the MFCs were continuously run for more than 3 weeks before the analysis.

\section{MFC design}

Both MFCs had the same size and configuration. Figure 1a shows the schematic diagram of an MFC. For each MFC system, two same-sized graphite carbon electrodes (CCM400C; Central Carbon Co., Ltd., Taiwan) were used for both anode and cathode $(6.3 \mathrm{~cm}$ length $\times 4 \mathrm{~cm}$ width $\times$ $3 \mathrm{~mm}$ thickness). Both anodic and cathodic chambers were made of Plexiglas acrylic sheets, and each chamber had an effective water volume of $797 \mathrm{~cm}^{3}(8.3 \mathrm{~cm}$ side water depth $\times 9.8 \mathrm{~cm}$ width $\times 9.8 \mathrm{~cm}$ length). The electrodes were fixed in the respective anodic and cathodic chambers by fully inserting them into the liquids in both chambers. All chambers were sealed with superglue. The covers and the connections of the anodic chamber were sealed with silicon to achieve anaerobicity in the chambers during operation.

A peristaltic pump was used to pump a fixed amount of synthetic wastewater into each anodic chamber. Inflow and outflow of each anodic chamber were located $1 \mathrm{~cm}$ above 
Fig. 1 Schematic diagram of an MFC and experimental design of this study

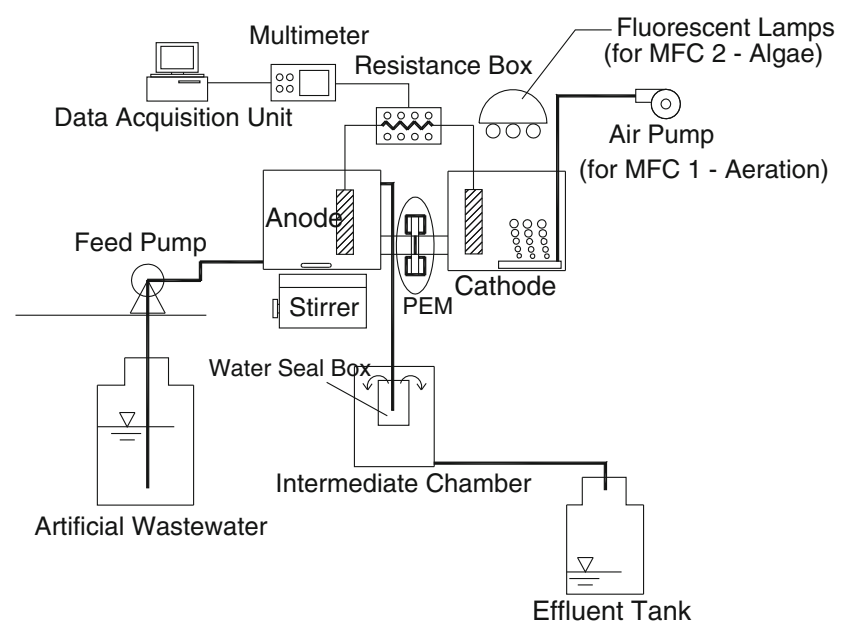

(Note: MFC 1 - oxygen provided from an air pump; MFC 2 - oxygen provided by algal photosynthesis) (a) Schematic diagram of an MFC

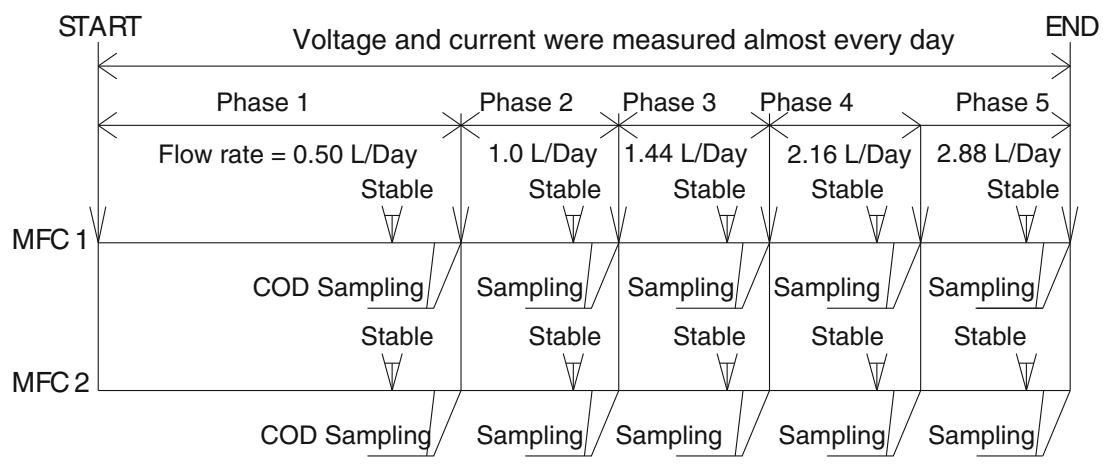

(b) Experimental design of this study

the bottom and $1 \mathrm{~cm}$ below the top of the chamber, respectively. The effluent of anodic chamber first flowed into a water seal box before overflowing into an intermediate chamber to ensure that the air will not reflux into the anodic chamber. The liquid in the intermediate chamber was then discharged to an effluent tank by gravity or collected for analysis.

The anodic and the cathodic chambers were separated by a proton exchange membrane (PEM) (Nafion 117, Dupont Co., USA) installed in a Plexiglas acrylic pipe (inner diameter $1.5 \mathrm{~cm}$ and total length $23 \mathrm{~cm}$ ) connecting anodic and cathodic chambers. The anode and the cathode were connected externally with concealed copper wire, and the power production was measured with external load resistance adjusted to $1000 \Omega$ using a resistor box. The distance between the anode and the cathode was approximately $36.5 \mathrm{~cm}$, which may be too large to obtain high power levels (Ghangrekar and Shinde 2007). However, the purpose of the present research was not to attain high power levels but to examine the behaviors of MFCs with different oxygen supplies in cathodic chamber. Both MFCs were also operated at the same time under the same operational conditions. Therefore, the results of the present study can be used to interpret and compare the power generation capabilities of the MFCs.

Operational condition

The MFCs were operated at an ambient temperature of $24-26^{\circ} \mathrm{C}$ in our laboratory. Both systems were run under identical continuous flow conditions at five different rates (Phase 1, 350; Phase 2, 700; Phase 3, 1000; Phase 4, 1500 and Phase 5, $2000 \mu \mathrm{L} / \mathrm{min}$ ) to compare their power generation capabilities. For the anodic chamber, hydraulic retention times (HRTs) at the five different flow rates were $38.3,19.1,13.3,8.9$, and 6.6 h, respectively. Figure $1 \mathrm{~b}$ shows the experimental design of the present study. Synthetic wastewater (influent) and effluents from the anodic chambers were collected for analysis. The performance of an MFC system was considered stable when both COD removal efficiency and power output are stable. The flow rate was set to $350 \mu \mathrm{L} / \mathrm{min}$ in Phase 1 . The voltages of each MFC were measured almost every day at external load resistance adjusted to $1000 \Omega$ until the system was stable. When the voltage readings became stable for a few days, influent and effluent water samples of MFCs and voltage 
readings during the last 2 days of Phase 1 were taken for COD analysis and power density calculation, respectively. The average COD concentration and the average voltage on both days were then used for the analysis (Fig. 1b). Similarly, MFC power production and water quality under the flow rates of 700 (Phase 2), 1000 (Phase 3), 1500 (Phase 4), and 2000 L/day (Phase 5) were evaluated.

To achieve the electrochemical reaction at the cathode, oxygen had to be supplied to the cathodic chamber. For MFC 1, air was purged into the cathodic chamber by an air stone connected to an air pump. The dissolved oxygen (DO) concentration was maintained at $6.78-7.45 \mathrm{mg} / \mathrm{L}$. The cathodic electrolyte used in the cathodic chamber was a mixture of $30.8 \mathrm{mM} \mathrm{KH} \mathrm{HO}_{4} \cdot \mathrm{H}_{2} \mathrm{O}$ solution (adjusted to $\mathrm{pH} 7.0$ by $1.0 \mathrm{~N} \mathrm{HNO}_{3}$ ) and aerated water. For MFC 2, green algae (Chlorella) and blue-green algae (Phormidium) were grown in the cathodic chamber. One gram of $\mathrm{KH}_{2} \mathrm{PO}_{4} \cdot \mathrm{H}_{2} \mathrm{O}$ and $1 \mathrm{~g}$ of $\mathrm{NH}_{4} \mathrm{CL}$ were added into the cathodic chamber of MFC 2 to serve as nutrients for algae in the beginning of Phase 1. About $0.1 \mathrm{~g}$ of $\mathrm{KH}_{2} \mathrm{PO}_{4} \cdot \mathrm{H}_{2} \mathrm{O}$ and $0.1 \mathrm{~g}$ of $\mathrm{NH}_{4} \mathrm{CL}$ were again added in the beginning of Phases 2-5. Two $6 \mathrm{~W}$ fluorescent lamps (12 $\mathrm{W}$ in total) were installed $15 \mathrm{~cm}$ above the water surface of the cathodic chamber to provide the light for photosynthesis. Oxygen in the cathodic chamber of MFC 2 was then produced by the photosynthesis of algae.

Sludge mixing in each anodic chamber was performed using a stirrer. However, mixing was very slow to reduce the substrate gradient and to provide effective contact between the substrate and the sludge. Mixing in the cathodic chamber of MFC 1 was only achieved through aeration. No mixing was provided in the cathodic chamber of MFC 2.

Analyses of water quality and power generation

The influents (synthetic wastewater) and the effluents of the anodic chambers were collected for water quality analyses. All effluent samples were filtered through filter papers (Whatman grade 934AH) before COD analysis. COD was determined using the closed reflux method mentioned in the Standard Methods (Clesceri et al. 2001). $\mathrm{pH}$, temperature, and DO (DO200; YSI, Inc., USA) of water in the cathodic chamber were also measured.
Voltages and currents (at adjusted external load resistance of $1000 \Omega$ ) were measured using a digital multimeter with a data acquisition unit (U1253B; Agilent Technologies, Malaysia). They were then converted to power ( $\mathrm{mW}$ ) and power density $\left(\mathrm{mW} / \mathrm{m}^{2}\right.$ surface area of anode plate). Voltage and current readings on the digital multimeter obtained using the data acquisition software Agilent GUI Data Logger (Agilent Technologies, Inc. USA) were allowed to stabilize for about 5-10 min before each measurement. The readings were continuously recorded every $10 \mathrm{~s}$ for $3 \mathrm{~min}$, and then averaged. The Coulombic efficiency $(\mathrm{Ce})$ was calculated as $\mathrm{Ce}=\mathrm{M} \times \mathrm{I} / \mathrm{F} \times \mathrm{n} \times \mathrm{q} \times$ $\Delta \mathrm{COD}$, where $M$ is the molecular weight of oxygen, $I$ is the current, $F$ is Faraday's constant, $n$ is the number of electrons exchanged per mole of oxygen, $q$ is the volumetric influent flow rate, and $\triangle \mathrm{COD}$ is the difference in the influent and the effluent COD. For the theoretical Coulombic amount calculations, four moles of electrons $(n=4)$ were produced per mole of COD in synthetic wastewater (Biffinger et al. 2008; Lee et al. 2008; Behera and Ghangrekar 2009; Rodrigo et al. 2009; Sun et al. 2009).

\section{Results and discussion}

\section{Wastewater treatment efficiencies}

Average COD removal rates and average COD degradation rates of both MFCs are outlined in Table 1. The influent COD concentrations of both MFCs were between 1002 and $1296 \mathrm{mg} / \mathrm{L}$. Both MFCs displayed very similar COD removal rates and COD degradation rates. COD removal rates decreased and COD degradation rates increased as flow rates increased from 350 to $2000 \mu \mathrm{L} / \mathrm{min}$. Lower flow rate means higher hydraulic retention time in the anodic chamber. Microorganisms in the anodic chamber had more time to degrade the substrate at lower flow rate and caused higher COD removal efficiency. However, as flow rate increased, the quantity of substrate entering the anodic chamber also increased. Therefore, the total amount of substrate degraded by the microorganisms (COD degradation rate) in the chamber increased as flow rate increased. As shown in Fig. 2, COD removal rate decreased as COD

Table 1 Average COD removal rates and degradation rates of both MFCs

\begin{tabular}{|c|c|c|c|c|c|}
\hline \multirow[t]{3}{*}{ Systems } & \multicolumn{5}{|c|}{ Influent flow rate $(\mu \mathrm{L} / \mathrm{min})$} \\
\hline & 350 & 700 & 1000 & 1500 & 2000 \\
\hline & \multicolumn{5}{|c|}{ Average COD removal rate $(\%) /$ Average COD degradation rate $\left(\mathrm{kg} \mathrm{COD} / \mathrm{m}^{3}\right.$ of anoxic chamber/day) } \\
\hline MFC 1 & $82.3 / 0.60$ & $55.7 / 0.73$ & $46.2 / 0.98$ & $40.0 / 1.20$ & $30.3 / 1.31$ \\
\hline MFC 2 & $89.3 / 0.65$ & $65.4 / 0.86$ & $45.9 / 0.93$ & $43.5 / 1.30$ & $32.9 / 1.43$ \\
\hline
\end{tabular}


Fig. 2 Relationships between COD removal rate and COD loading and between COD degradation rate and COD loading on both MFCs

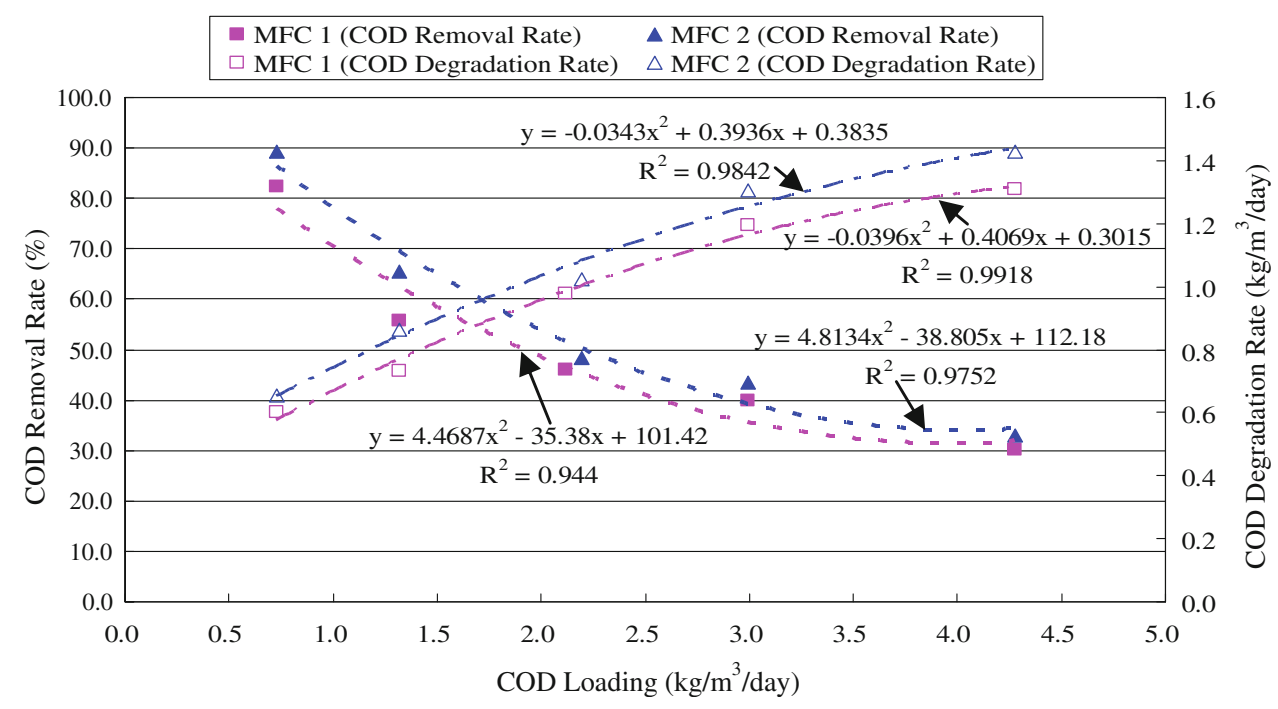

loading increased. However, COD degradation rate increased when COD loading increased. The relationships between COD removal rate and COD loading for MFCs 1 and 2 can be expressed as binary quadratic equations. The coefficients of determination $\left(R^{2}\right)$ were 0.9440 and 0.9750 for MFCs 1 and 2, respectively. In MFCs 1 and 2, binary quadratic equations can also be used to express the relationship between COD degradation rate and COD loading $\left(R^{2}=0.9918\right.$ and 0.9842 for MFCs 1 and 2, respectively). Therefore, MFC can be applied as a biosensor to predict the COD removal rate or the COD degradation rate by measuring the COD loading. In this study, the influent $\mathrm{pH}$ was between 6.23 and 7.58 , and the effluent $\mathrm{pH}$ was in the range of 4.64-7.12 and 5.54-7.25 for MFCs 1 and 2, respectively. The DO concentration in the cathodic chamber of MFC 1 was between 6.78 and $7.45 \mathrm{mg} / \mathrm{L}$, and its concentration in the cathodic chamber of MFC 2 was between 3.89 and $5.95 \mathrm{mg} / \mathrm{L}$.

Effects of influent flow rate on MFC performance

As shown in Fig. 3a, a good linear relationship $\left(R^{2}=\right.$ 0.9988 ) between voltage and flow rate on MFC 1 with external resistance of $1000 \Omega$ was found. The voltage output of MFC 1 increased when its influent flow rate increased from 350 to $2000 \mu \mathrm{L} / \mathrm{min}$. However, linear relationship between voltage and flow rate is low on MFC $2\left(R^{2}=0.543\right)$, with external load resistance of $1000 \Omega$. Similarly, as shown in Fig. 3b, good linear relationship between power density and flow rate $\left(R^{2}=0.9925\right)$ was only found on MFC 1 with external resistance of $1000 \Omega$, not on MFC $2\left(R^{2}=0.5743\right)$. In Fig. 3, MFC 1 displayed higher voltage output and higher power density than MFC 2 at the flow rates between 350 and $2000 \mu \mathrm{L} / \mathrm{min}$. Operational conditions are the same for MFCs 1 and 2, so DO variation in the cathodic chamber is presumed to be one of the reasons for the unstable power output of MFC 2. Furthermore, some of the algae or their biochemical products might have passed through PEM to the anodic chamber and affected the overall power generation performance of MFC 2. Further studies are required to confirm our presumptions.

Effects of COD loading on MFC performance

Figure 4a shows a good linear relationship $\left(R^{2}=0.9966\right)$ between voltage and COD loading on MFC 1 (external load resistance $=1000 \Omega$ ). As COD loading increased from 0.731 to $4.278 \mathrm{~kg} / \mathrm{m}^{3} /$ day, voltage for MFC 1 increased from 55.22 to $86.44 \mathrm{mV}$. A good linear relationship $\left(R^{2}=0.9956\right)$ between power density and COD loading on MFC 1 is also presented in Fig. 4b. As COD loading increased from 0.731 to $4.278 \mathrm{~kg} / \mathrm{m}^{3} /$ day, power density for MFC 1 increased from 0.556 to $1.368 \mathrm{~mW} / \mathrm{m}^{2}$ of anode plate surface. However, linear relationships between voltage and COD loading and between power density and COD loading in the range of $0.731-4.278 \mathrm{~kg} / \mathrm{m}^{3} /$ day were low on MFC $2\left(R^{2}=0.6156\right.$ and 0.6432 , respectively). According to the regression equations in Fig. 4, MFC 1 displayed higher voltage output and higher power density than MFC 2 (also see the slopes of the regression equations). As mentioned above, unstable and lower DO concentration in the cathodic chamber of MFC 2 might be the reason for its lower voltage output and lower power density.

Relationships between power output and COD removal rate on MFCs

The relationships between voltage and COD removal rate on MFCs 1 and 2 with external load resistance of $1000 \Omega$ can be expressed as binary quadratic equations shown in 
Fig. 3 a Relationships between voltage and flow rate and b between power density and flow rate on both MFCs
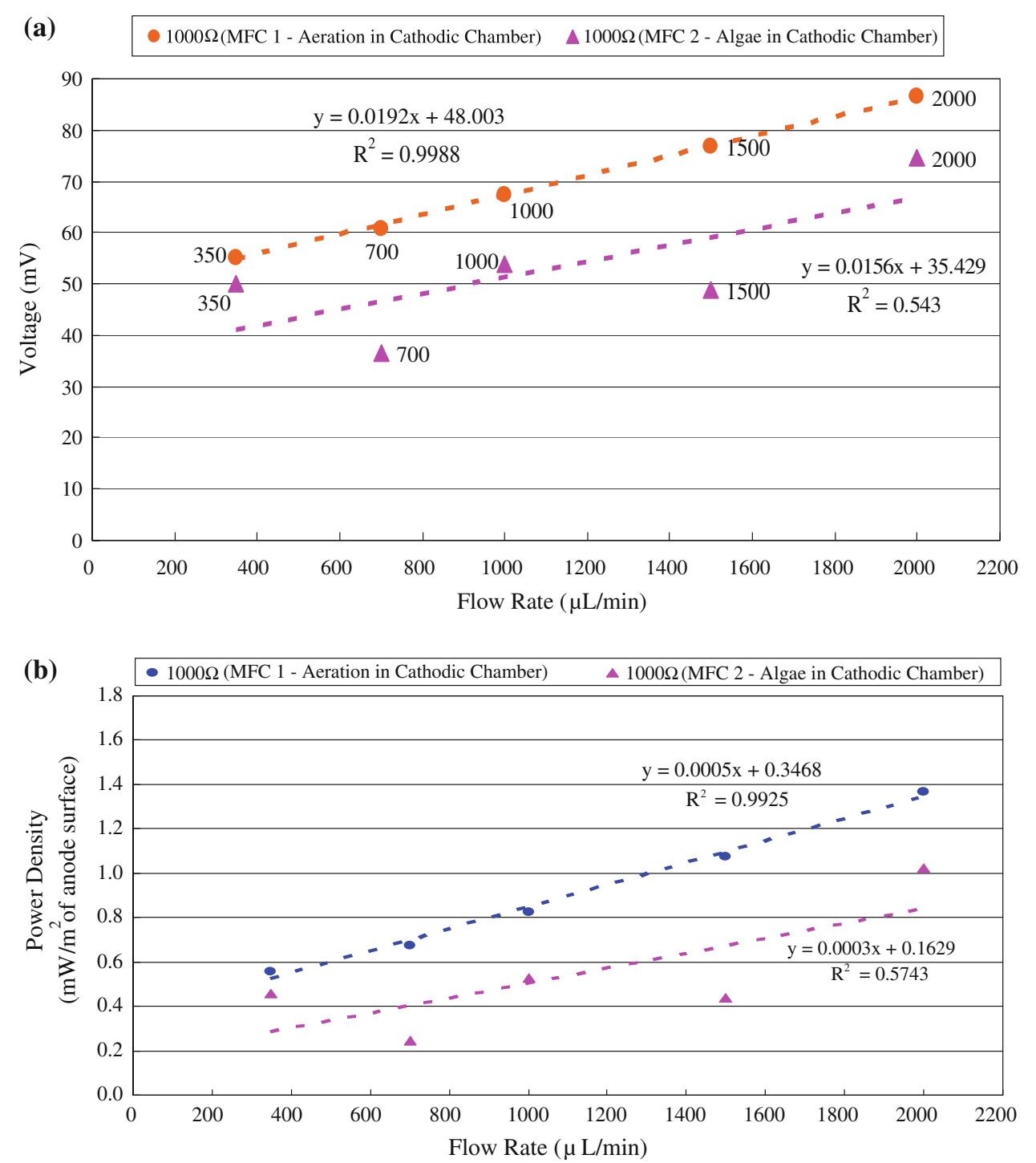

Fig. 5a. $R^{2}$ values were 0.9904 and 0.9159 for MFCs 1 and 2 , respectively. Figure $5 \mathrm{~b}$ also shows similar relationships between power density and COD removal rate on MFCs 1 and $2\left(R^{2}=0.9925\right.$ and 0.9081 for MFCs 1 and 2, respectively). This means that, with the development of these binary quadratic equations, both MFCs can be used as biosensors to predict COD removal rate by measuring their voltage or power density.

Relationships between power output and COD degradation rate on MFCs

The relationship between voltage and COD degradation rate on MFC 1 with external load resistance of $1000 \Omega$ can be expressed as a linear equation, as shown in Fig. 6a, with $R^{2}=0.9653$. Figure $6 \mathrm{~b}$ also shows a good linear relationship between power density and COD degradation rate on MFC $1\left(R^{2}=0.9396\right)$. This also means that, with the development of these linear equations, MFC 1 can be used as a biosensor to predict COD degradation rate by measuring its voltage or power density. However, the relationships between voltage and COD degradation rate and between power density and COD degradation rate for MFC 2 with external load resistance of $1000 \Omega$ could not be well expressed as linear equations $\left(R^{2}=0.4244\right.$ and 0.4439 , respectively), as shown in Fig. 6a, b.

Relationships between power output and effluent COD concentration on MFCs

The relationship between voltage and effluent COD concentration on MFC 1 with external load resistance of $1000 \Omega$ can also be expressed as a binary quadratic equation, as shown in Fig. 7a, with $R^{2}=0.9428$. Figure $7 \mathrm{~b}$ also 
Fig. 4 Effects of COD loading on the voltage output and the power density of both MFCs (a)

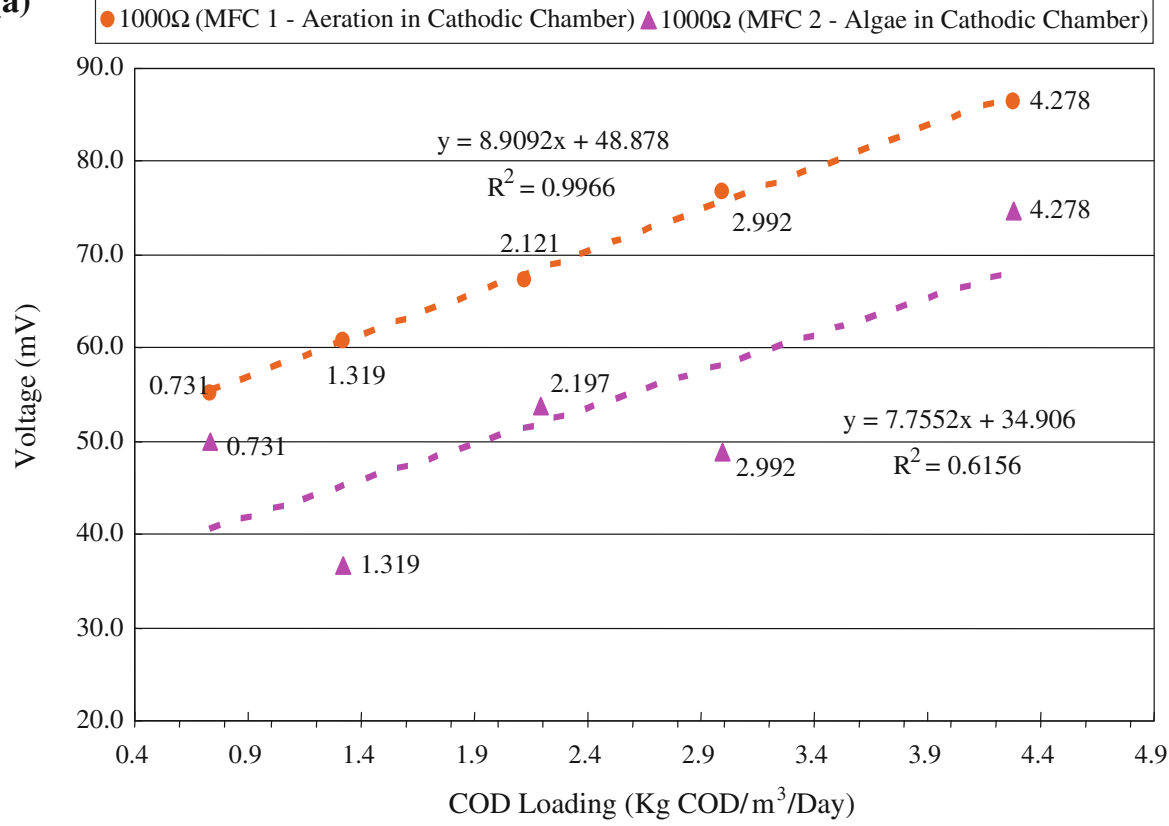

(b) $1000 \Omega$ (MFC 1 - Aeration in Cathodic Chamber) $\Delta 1000 \Omega$ (MFC 2 - Algae in Cathodic Chamber)

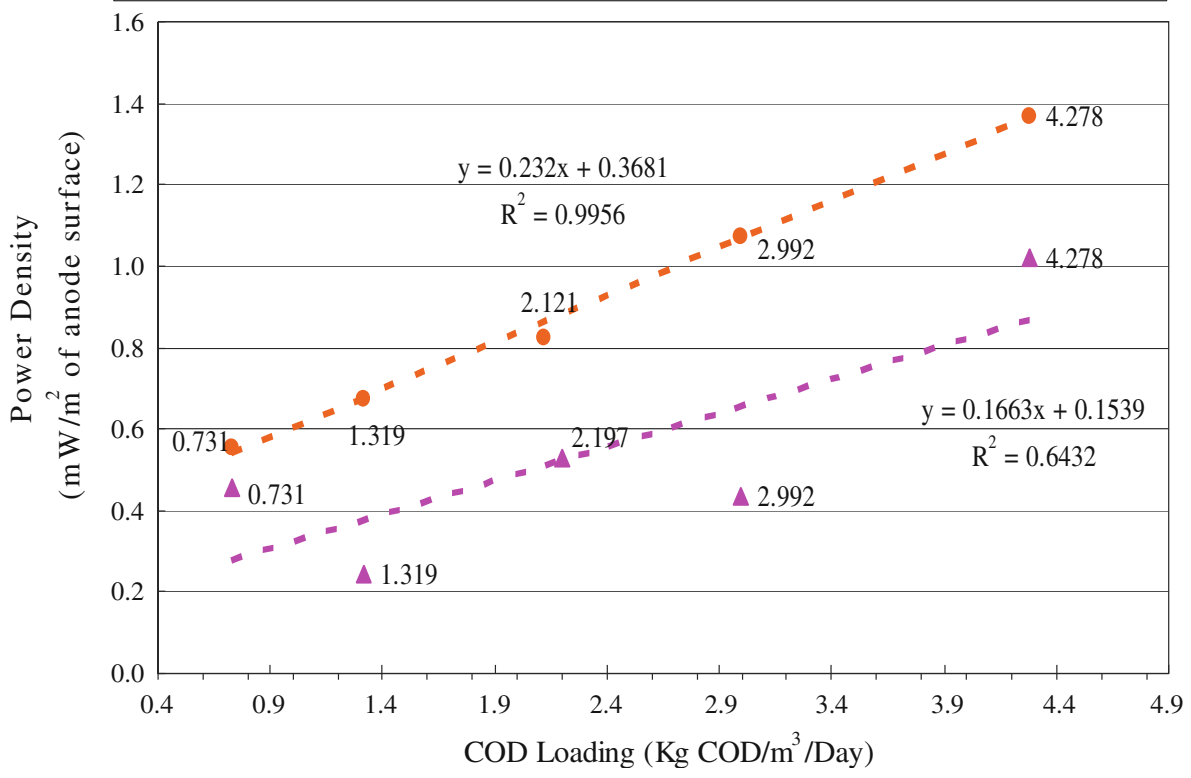

shows a similar relationship between power density and effluent COD concentration on MFC $1\left(R^{2}=0.9256\right)$. This also means that, with the development of the binary quadratic equations, MFC 1 can be used as a biosensor to predict the effluent COD concentration by measuring its voltage or power density. The relationships between voltage and effluent COD concentration and between power density and effluent COD concentration for MFC 2 with external load resistances of $1000 \Omega$ can also be expressed as binary quadratic equations, as shown in Fig. 7a, b, with $R^{2}=0.7808$ and 0.7985 , respectively. This also means that, with the development of these binary quadratic equations, MFC 2 can also be used as a biosensor to roughly predict the effluent COD concentration by measuring its voltage or power density.

Coulombic efficiency of MFCs

Coulombic efficiency can be used to express the efficiency of power production per unit of organic matter utilized by a microorganism (Min and Logan 2004). Figure 8a shows a binary quadratic equation can be used to display the relationship between Coulombic efficiency and flow rate in MFC 1 at external load resistance of $1000 \Omega\left(R^{2}=0.9695\right)$. 
Fig. 5 a Relationships between voltage and COD removal rate and $\mathbf{b}$ between power density and COD removal rate on both MFCs (a)
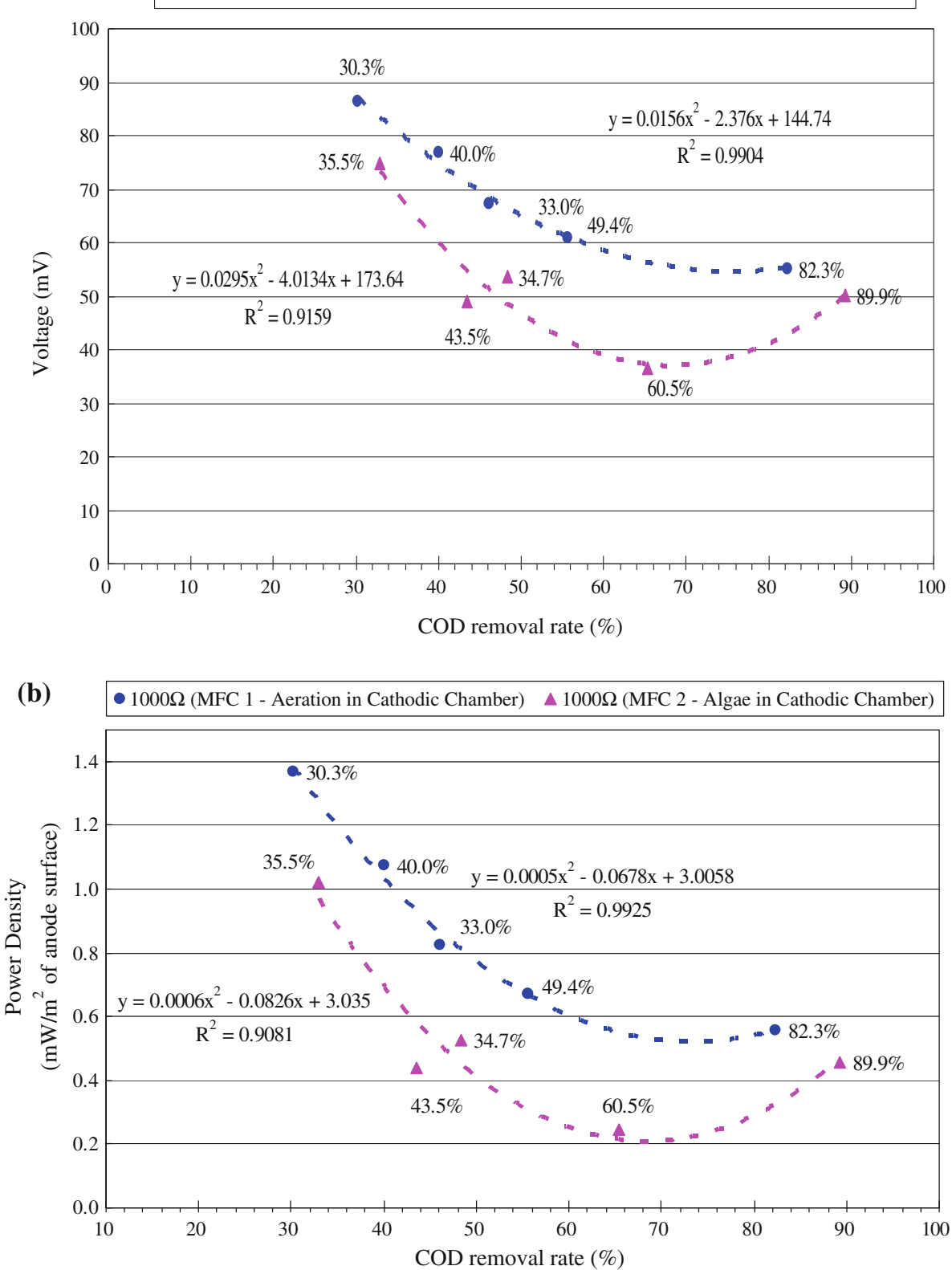

However, the relationship between Coulombic efficiency and flow rate for MFC 2 with external load resistances of $1000 \Omega$ cannot be expressed well into a binary quadratic equation $\left(R^{2}=0.5743\right)$, as shown in Fig. 8a. These results were contrary to the relationships between voltage and flow rate and between power density and flow rate on MFCs 1 and 2, as shown in Fig. 3. For MFC 1, the highest Coulombic efficiency was seen at influent flow rate of $350 \mu \mathrm{L} / \mathrm{min}$ and the lowest value was seen at $1500 \mu \mathrm{L} / \mathrm{min}$. For MFC 2, the highest Coulombic efficiency was seen at flow rate of $350 \mu \mathrm{L} / \mathrm{min}$, and the lowest value was also seen at $1500 \mu \mathrm{L} /$ min. Normally, a MFC is expected to obtain higher power density and higher Coulombic efficiency. If the relationship between power density and flow rate for MFCs 1 and 2 (with the external resistance of $1000 \Omega$ ) is as illustrated in Fig. 8, then the optimum flow rates to obtain higher power density and higher Coulombic efficiency in MFC $1\left(=0.85 \mathrm{~mW} / \mathrm{m}^{2}\right.$ and $0.063 \%)$ and in MFC $2\left(=0.65 \mathrm{~mW} / \mathrm{m}^{2}\right.$ and $\left.0.05 \%\right)$ are about 1000 and $1460 \mu \mathrm{L} / \mathrm{min}$, respectively.

The relationship between Coulombic efficiency and effluent COD concentration was shown in Fig. 8b, respectively. Binary quadratic equation can well express the relationship between Coulombic efficiency and effluent COD concentration $\left(R^{2}=0.906\right)$ on MFC 1 . However, it 
Fig. 6 a Relationships between voltage and COD degradation rate and $\mathbf{b}$ between power density and COD degradation rate on both MFCs (a)

- $1000 \Omega$ (MFC 1 - Aeration in Cathodic Chamber) $\triangle 1000 \Omega$ (MFC 2 - Algae in Cathodic Chamber)

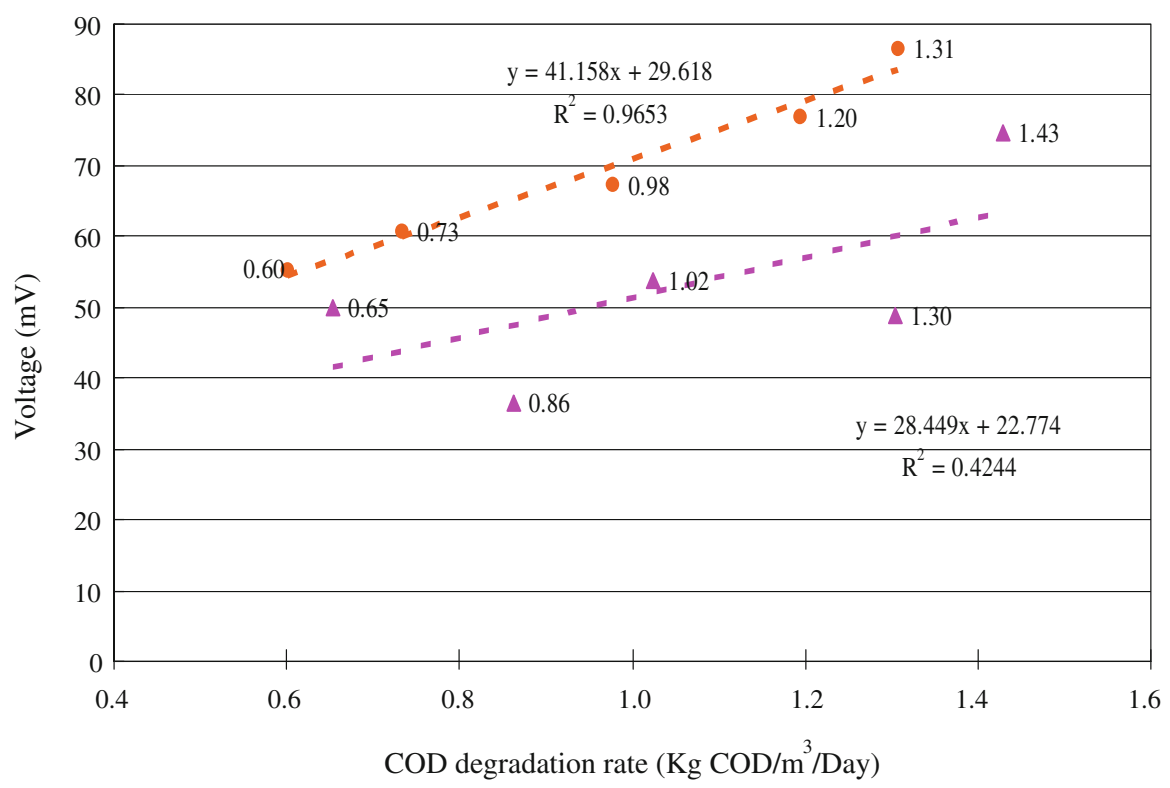

(b) $1000 \Omega($ MFC 1 - Aeration in Cathodic Chamber $) \triangle 1000 \Omega$ (MFC 2 - Algae in Cathodic Chamber $)$

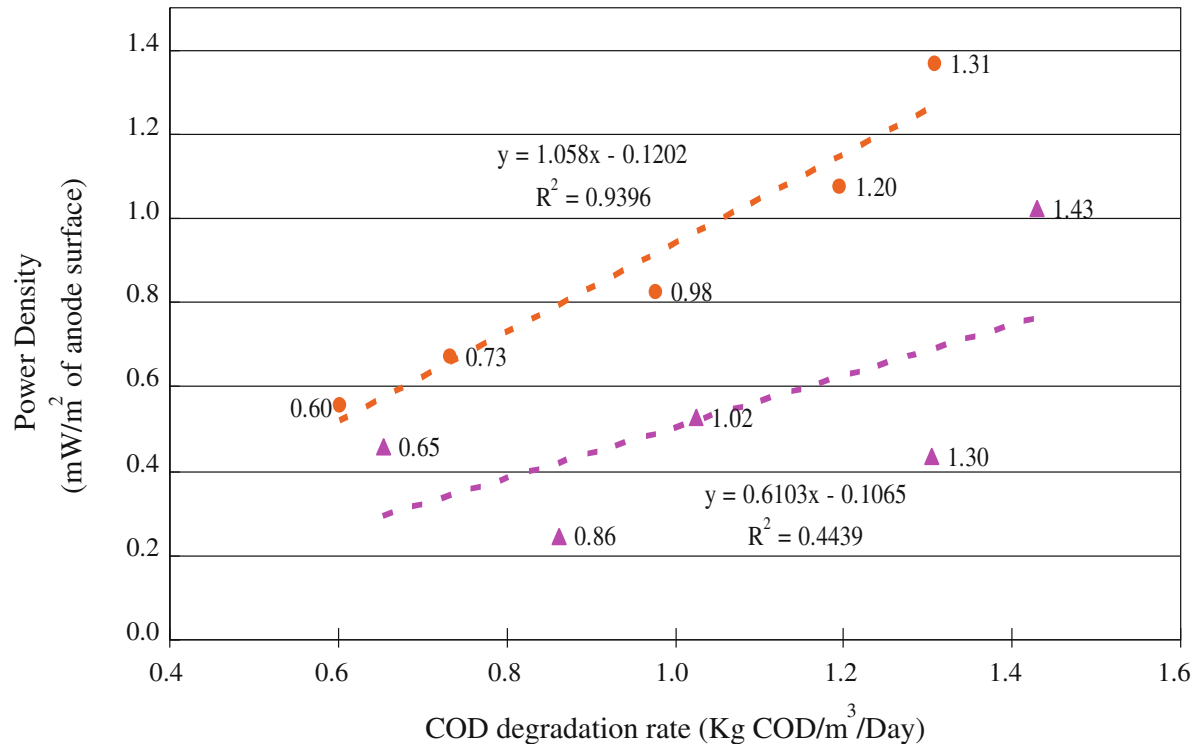

may not be used to express the relationship between Coulombic efficiency and effluent COD concentration $\left(R^{2}=0.1746\right)$ on MFC 2.

Figure 9a also shows the relationship between Coulombic efficiency and COD removal rate on MFC 1 with external load resistance of $1000 \Omega$ can also be expressed as a binary quadratic equation $\left(R^{2}=0.8431\right)$. However, the relationship between Coulombic efficiency and COD removal rate for MFC 2 with external load resistances of $1000 \Omega$ cannot be expressed well into a binary quadratic equation $\left(R^{2}=0.1558\right)$. For MFC 1 , the highest Coulombic efficiency was seen at the COD removal rate of $30.3 \%$, and the lowest value was seen at the COD removal rate of about $72 \%$. For MFC 2, the highest Coulombic efficiency was seen at the COD removal rate of $30.3 \%$, and the lowest value was seen at about $65 \%$. These results were also contrary to the relationships between voltage and COD removal rate and between power density and COD removal rate on MFCs 1 and 2, as shown in Fig. 5. If the relationships between power density and COD removal 
Fig. 7 a Relationship between voltage and effluent COD concentration and $\mathbf{b}$ relationship between power density and effluent COD concentration on both MFCs
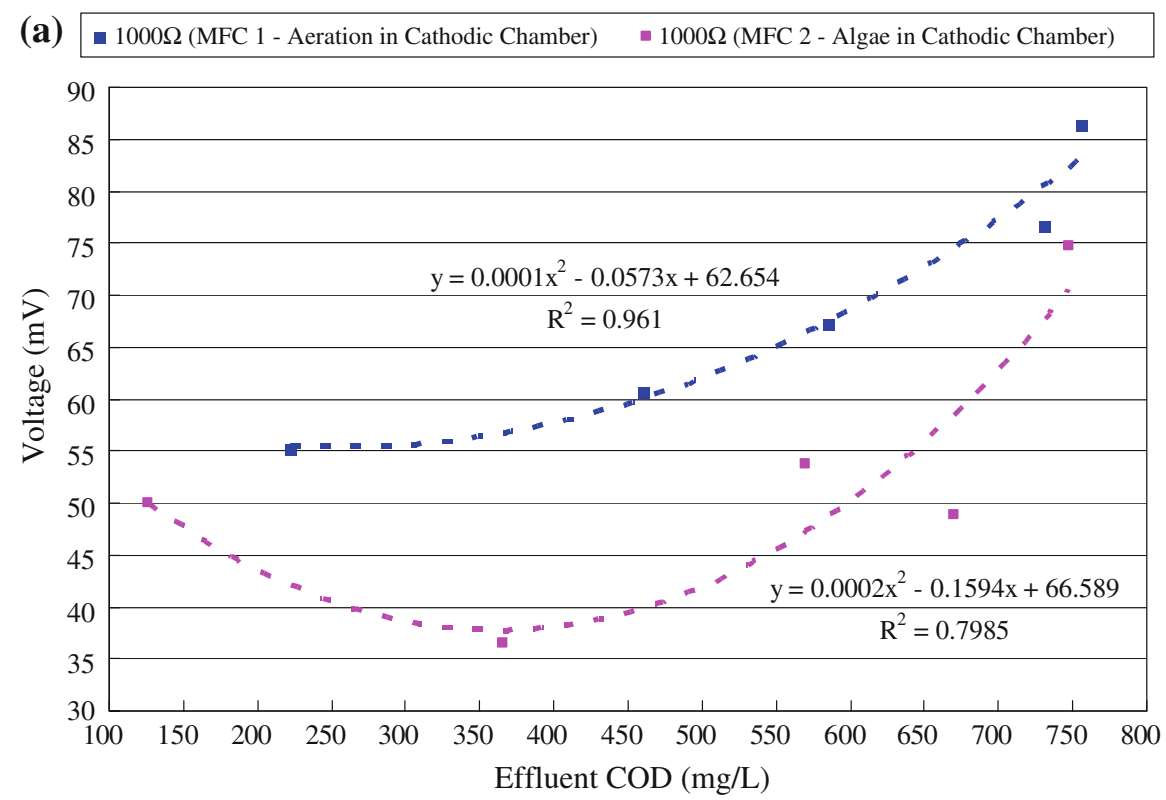

(b) $\quad 1000 \Omega$ (MFC 1 - Aeration in Cathodic Chamber) $=1000 \Omega($ MFC 2 - Algae in Cathodic Chamber)

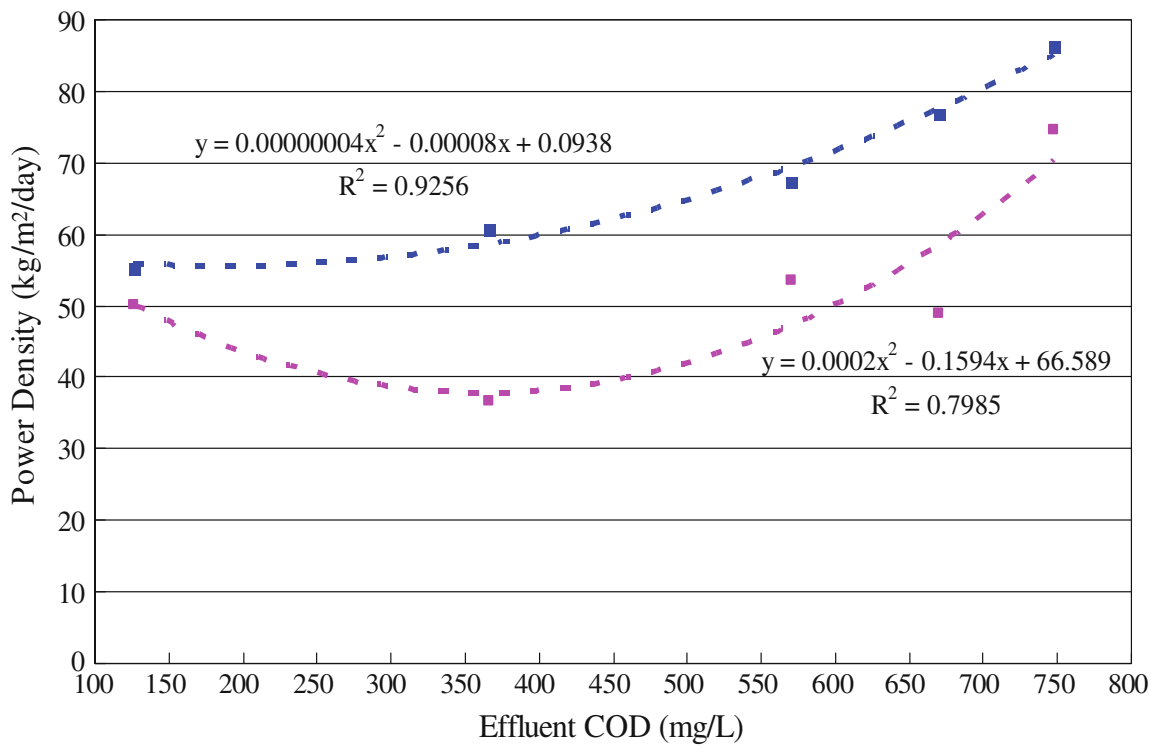

rate for MFCs 1 and 2 (with external resistance of $1000 \Omega$ ) are also illustrated in Fig. 9a, then the optimum COD removal rates to obtain higher power density and higher Coulombic efficiency in MFC $1 \quad\left(=1.2 \mathrm{~mW} / \mathrm{m}^{2}\right.$ and $0.064 \%)$ and in MFC $2\left(=0.81 \mathrm{~mW} / \mathrm{m}^{2}\right.$ and $\left.0.051 \%\right)$ are about 40.5 and $36.5 \%$, respectively. Figure $9 \mathrm{~b}$ also shows the relationship between Coulombic efficiency and COD degradation rate on MFC 1 with external load resistance of $1000 \Omega$ can also be expressed as a binary quadratic equation $\left(R^{2}=0.9895\right)$. However, the relationship between Coulombic efficiency and COD degradation rate for MFC 2 with external load resistances of $1000 \Omega$ cannot be expressed well into a binary quadratic equation $\left(R^{2}=0.2872\right)$.

The differences in Coulombic efficiency mean that some electrons are consumed by some mechanisms other than the cathode reaction (Gil et al. 2003). In this study, the Coulombic efficiency was always higher on MFC 1 than on MFC 2. Therefore, Coulombic efficiency or power generation efficiency should be higher for the cathodic chamber with higher DO concentration than the one with lower DO concentration. 
Fig. 8 a Relationship between Coulombic efficiency and flow rate and $\mathbf{b}$ relationship between Coulombic efficiency and effluent COD concentration on both MFCs (a)

- $1000 \Omega$ (MFC 1 - Coulombic Efficiency) $\Delta 1000 \Omega$ (MFC 2 - Coulombic Efficiency)

- $1000 \Omega$ (MFC 1 - Power Density)

- $1000 \Omega$ (MFC 2 - Power Density)

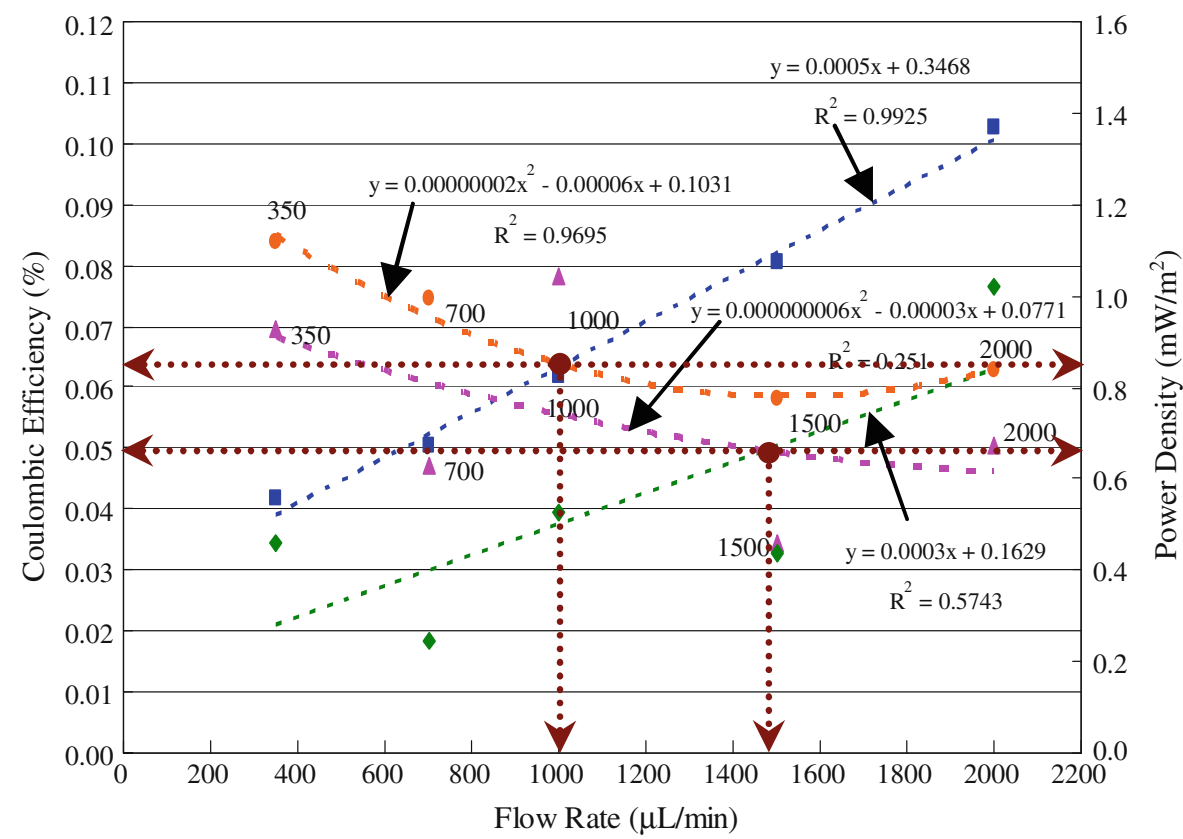

(b) $1000 \Omega$ (MFC 1 - Aeration in Cathodic Chamber) $\quad 1000 \Omega$ (MFC 2 - Algae in Cathodic Chamber)

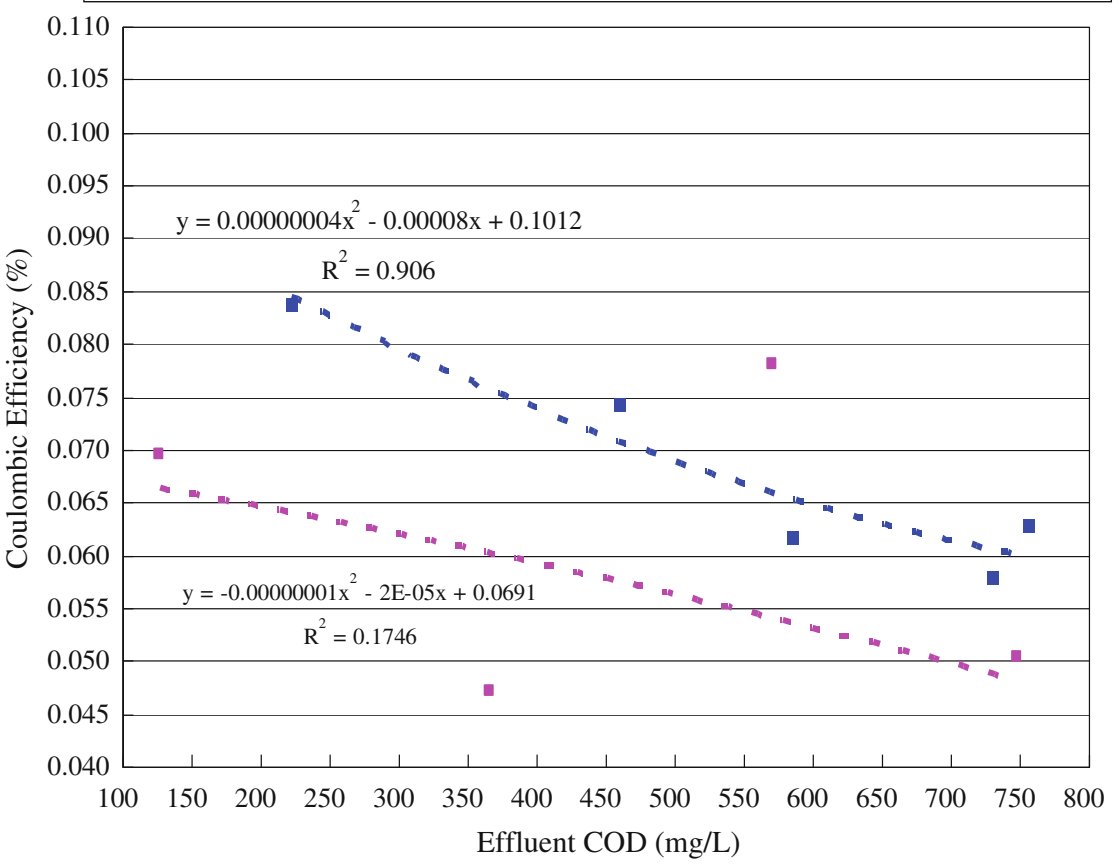

\section{Conclusion}

MFC 1 with the mechanical aeration and MFC 2 with the photosynthesis of algae in cathodic chamber displayed very similar COD removal rates and COD degradation rates. In both MFCs, COD removal rates decreased and COD degradation rates increased as flow rates increased. The relationships between COD removal rate and COD loading and between COD degradation rate and COD loading for MFCs 1 and 2 can be expressed as binary quadratic equations. Therefore, MFC can be applied as a biosensor to predict the COD removal rate or the COD degradation rate by measuring the COD loading. 
Fig. 9 a Relationship between Coulombic efficiency and COD removal rate and $\mathbf{b}$ relationship between Coulombic efficiency and COD degradation rate on both MFCs

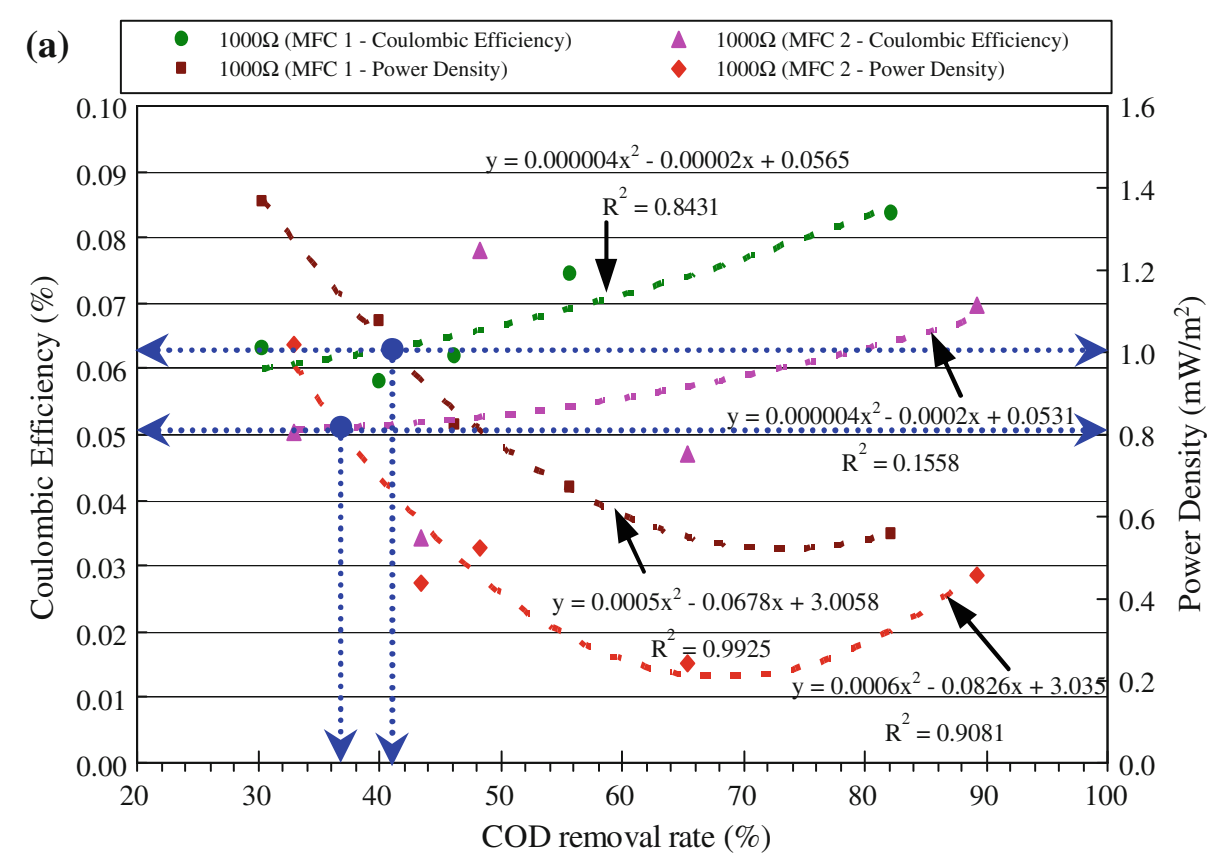

(b) $1000 \Omega($ MFC 1 - Aeration in Cathodic Chamber $) \triangle 1000 \Omega($ MFC $2-$ Algae in Cathodic Chamber $)$

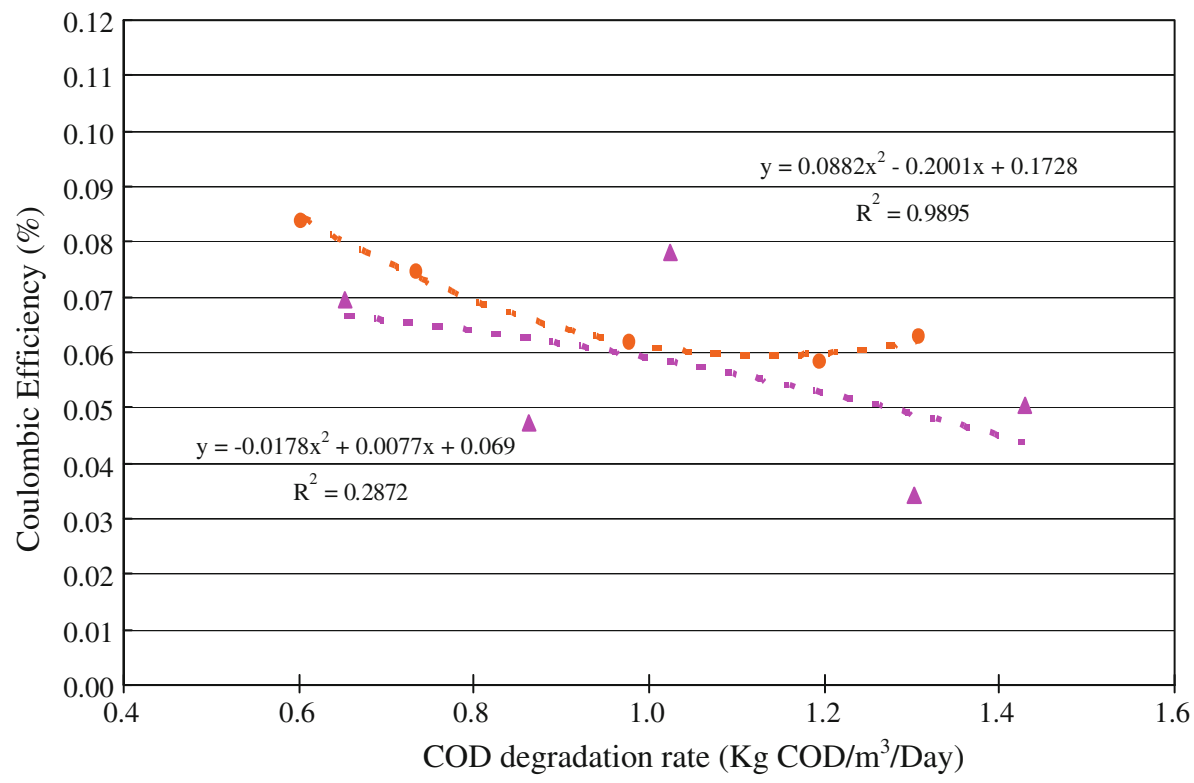

Good linear relationships between voltage and flow rate and between power density and flow rate with external resistance of $1000 \Omega$ were only found on MFC 1 , not on MFC 2. DO variation in the cathodic chamber is presumed to be one of the reasons for the unstable power output of MFC 2. Besides, some of the algae or their biochemical products might have passed through PEM to the anodic chamber and affected the overall power generation performance of MFC 2. Further studies are required to confirm our presumptions. Similarly, good linear relationships between voltage and COD loading and between power density and COD loading were only found on MFC 1, not on MFC 2. Also, good linear relationships between voltage and COD degradation rate and between power density and COD degradation rate were only found on MFC 1 , not on MFC 2. However, the relationships between voltage and COD removal rate and between power density and COD removal rate on MFC 1 and MFC 2 with external load resistance of $1000 \Omega$ can be expressed as binary quadratic equations. Similarly, the relationships between voltage and 
effluent COD concentration and between power density and effluent COD concentration on MFCs 1 and 2 with external load resistance of $1000 \Omega$ can also be expressed as binary quadratic equations. Therefore, with the development of these linear and binary quadratic equations, MFC can be used as a biosensor to predict its treatment efficiency of organic matters by measuring its voltage or power density.

The relationship between Coulombic efficiency and flow rate in MFC 1 with external load resistances of $1000 \Omega$ can be expressed as a binary quadratic equation. However, the relationship between Coulombic efficiency and flow rate for MFC 2 with external load resistances of $1000 \Omega$ cannot be expressed well into a binary quadratic equation. Since the relationship between power output (voltage or power density) and flow rate is contrary to the relationship between Coulombic efficiency and flow rate, an optimum flow rate can be found to obtain higher power density and higher Coulombic efficiency in the meantime. The optimum flow rates to obtain higher power density and higher Coulombic efficiency in MFC $1(=0.85 \mathrm{~mW} /$ $\mathrm{m}^{2}$ and $\left.0.063 \%\right)$ and in MFC $2\left(=0.65 \mathrm{~mW} / \mathrm{m}^{2}\right.$ and $0.05 \%)$ are about 1000 and $1460 \mu \mathrm{L} / \mathrm{min}$, respectively. Similarly, since the relationship between power output (voltage or power density) and COD removal rates is contrary to the relationship between Coulombic efficiency and COD removal rates, the optimum COD removal rates to obtain higher power density and higher Coulombic efficiency in MFC $1\left(=1.2 \mathrm{~mW} / \mathrm{m}^{2}\right.$ and $\left.0.064 \%\right)$ and in MFC $2\left(=0.81 \mathrm{~mW} / \mathrm{m}^{2}\right.$ and $\left.0.051 \%\right)$ are about 40.5 and $36.5 \%$, respectively.

Acknowledgments The authors would like to express their gratitude and appreciation to the National Science Council (NSC) of Taiwan for the financial support of this research under Contract No. NSC-99-2221-E-276-004-.

\section{References}

Behera M, Ghangrekar MM (2009) Performance of microbial fuel cell in response to change in sludge loading rate at different anodic feed $\mathrm{pH}$. Bioresour Technol 100(21):5114-5121

Biffinger JC, Byrd JN, Dudley BL, Ringeisen BR (2008) Oxygen exposure promotes fuel diversity for Shewanella oneidensis microbial fuel cells. Biosens Bioelectron 23:820-826

Cha J, Choi S, Yu H, Kim H, Kim C (2009) Directly applicable microbial fuel cells in aeration tank for wastewater treatment. Bioelectrochemistry 78(1):72-79

Clesceri LS, Greenberg AE, Eaton AD (2001) Standard methods for the examination of water and wastewater, American Public Health Association (APHA). American Water Works Association (AWWA) and Water Environment Federation (WEF)

Dewan A, Donovan C, Heo D, Beyenal H (2010) Evaluating the performance of microbial fuel cells powering electronic devices. J Power Sources 195(1):90-96
Ghangrekar MM, Shinde VB (2007) Performance of membrane-less microbial fuel cell treating wastewater and effect of electrode distance and area on electricity production. Bioresour. Tech 98(15):2879-2885

Gil GC, Chang IS, Kim BH, Kim M, Jang JK, Park HS, Kim HJ (2003) Operational parameters affecting the performance of a mediator-less microbial fuel cell. Biosens Bioelectron 18(4): 327-334

Ieropoulos I, Winfield J, Greenman J (2010) Effects of flow-rate, inoculum and time on the internal resistance of microbial fuel cells. Bioresour Technol 101(10):3520-3525

Juang DF, Chiou LJ (2007) Microbial population structures in activated sludge before and after the application of synthetic polymer. Int J Environ Sci Technol 4(1):119-125

Kang KH, Jang JK, Pham TH, Moon H, Chang IS, Kim BH (2003) A microbial fuel cell with improved cathode reaction as a low biochemical oxygen demand sensor. Biotechnol Lett 25(16): 1357-1361

Kim HJ, Park HS, Hyun MS, Chang IS, Kim M, Kim BH (2002) A mediator-less microbial fuel cell using a metal reducing bacterium, Shewanella putrefacians. Enzyme Microb Technol 30:145-152

Lee HS, Parameswaran P, Kato-Marcus A, Torres CI, Rittmann BE (2008) Evaluation of energy-conversion efficiencies in microbial fuel cells (MFCs) utilizing fermentable and non-fermentable substrates. Water Res 42(6-7):1501-1510

Logan BE (2005) Simultaneous wastewater treatment and biological electricity generation. Water Sci Technol 52(1):31-37

Logan BE, Regan JM (2006) Electricity-producing bacterial communities in microbial fuel cells. Trends Microbiol 14(12):512-518

Min B, Logan BE (2004) Continuous electricity generation from domestic wastewater and organic substrates in a flat plate microbial fuel cell. Environ Sci Technol 38(21):5809-5814

Oh S, Logan BE (2006) Proton exchange membrane and electrode surface areas as factors that affect power generation in microbial fuel cells. Appl Microbiol Biotechnol 70(2):162-169

Oh S, Min B, Logan BE (2004) Cathode performance as a factor in electricity generation in microbial fuel cells. Environ Sci Technol 38(18):4900-4904

Pham TH, Jang JK, Chang IS, Kim BH (2004) Improvement of cathode reaction of a mediatorless microbial fuel cell. J Microbiol Biotech 14(2):324-329

Rabaey K, Verstraete W (2005) Microbial fuel cells: novel biotechnology for energy generation. Trends Biotech 23(6):291-298

Rodrigo MA, Cañizares P, García H, Linares JJ, Lobato J (2009) Study of the acclimation stage and of the effect of the biodegradability on the performance of a microbial fuel cell. Bioresour Technol 100(20):4704-4710

Rodrigo MA, Cañizares P, Lobato J (2010) Effect of the electronacceptors on the performance of a MFC. Bioresour Technol 101(18):7014-7018

Rosenbaum M, He Z, Angenent LT (2010) Light energy to bioelectricity: photosynthetic microbial fuel cells. Curr Opin Biotechnol 21(3):259-264

Schamphelaire LD, Verstraete W (2009) Revival of the biological sunlight-to-biogas energy conversion system. Biotechnol Bioeng 103(2):296-304

Strik DPBTB, Terlouw H, Hamelers HVM, Buisman CJN (2008) Renewable sustainable biocatalyzed electricity production in a photosynthetic algal microbial fuel cell (PAMFC). Appl Microbiol Biotechnol 81(4):659-668

Sun J, Hu Y, Bi Z, Cao Y (2009) Improved performance of aircathode single-chamber microbial fuel cell for wastewater treatment using microfiltration membranes and multiple sludge inoculation. J Power Sources 187(2):471-479 
Wang X, Feng Y, Liu J, Lee H, Li C, Li N, Ren N (2010) Sequestration of $\mathrm{CO} 2$ discharged from anode by algal cathode in microbial carbon capture cells (MCCs). Biosens Bioelectron 25(12):2639-2643
You SJ, Zhao QL, Jiang JQ, Zhang JN (2006) Treatment of domestic wastewater with simultaneous electricity generation in microbial fuel cell under continuous operation. Chem Biochem Eng Q 20(4):407-412 